\title{
ORIGINAL RESEARCH

PHYSICAL THERAPY FOLLOWING ANTERIOR CERVICAL
DISCECTOMY AND FUSION: A STUDY OF CURRENT
CLINICAL PRACTICE AND THERAPIST BELIEFS

${ }^{1}$ Brian T. Swanson

${ }^{2}$ Robin R. Leger

\section{ABSTRACT}

Background: Anterior cervical discectomy and fusion (ACDF) is a commonly performed surgical procedure. However, there is substantial debate regarding the role of physical therapy following this procedure. Therefore, we sought to determine current physical therapy practice following ACDF surgery, as well as determine physical therapists beliefs regarding rehabilitation following ACDF.

Methods: One hundred and eighty three licensed Physical Therapists were invited to participate in a descriptive internet based survey; a total of 53 (29\%) completed the survey. Physical Therapists were assessed for their current practice, asked to rate the clinical usefulness of various treatment modalities, and indicate their recommendations regarding post-operative physical therapy for subjects following anterior discectomy and fusion. Results were then assessed for frequency distributions, with chi-square analysis for association between demographic data and practice recommendations.

Results: The results indicate that Physical Therapists believe patients achieve superior outcomes with the inclusion of post-operative physical therapy, with a low risk of harm. Specific treatments indicated as most useful included endurance exercise (60.4\%), isometric strengthening (56.6\%), and stretching (45.3\%). Other treatment options are discussed in detail.

Conclusion: Physical Therapists identified specific activities that they felt were most appropriate for rehabilitation following ACDF surgery. These findings may help to direct both appropriate therapy prescription following ACDF, as well as future research.

Keywords: Cervical spine surgery, ACDF, physical therapy, practice patterns, evidenced-based practice.

Received $28^{\text {th }}$ February 2015, revised $27^{\text {th }}$ March 2015, accepted $31^{\text {st }}$ March 2015

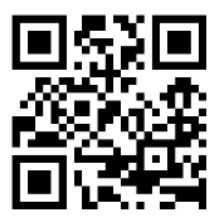

DOI: 10.15621/ijphy/2015/v2i2/65249

www.ijphy.org

CORRESPONDING AUTHOR

${ }^{1}$ Brian T. Swanson

${ }^{2} \mathrm{RN}, \mathrm{MS}, \mathrm{PhD}$

Associate Professor, Graduate School of Nursing, Salem State University,

Salem, MA, USA.

PT, DSc, FAAOMPT

Texas Woman's University,

School of Physical Therapy,

Houston, TX, USA. 


\section{INTRODUCTION}

Anterior cervical decompression and fusion (ACDF) has been shown to be successful in the management of cervical disc disease. ${ }^{1}$ While there is general agreement among both physicians and physical therapists that patients undergoing cervical spine surgery need regular follow up, postsurgical rehabilitation recommendations following cervical spine surgery have not been well established. Physical therapy is commonly utilized during both the pre and post-operative period, with approximately $70 \%$ of surgeons regularly utilizing physical therapy services, according to our previous survey of the members of the North American Spine Society. ${ }^{2}$ Despite being frequently used, the effect of rehabilitation following ACDF on patient reported outcomes is unknown.

Few prospective studies have been published with respect to outcomes and disability following ACDF. ${ }^{3}$ While generally successful in the treatment of radicular symptoms, with over $75 \%$ reporting relief at 2 years post-operatively, ${ }^{4-6}$ it is not uncommon for patients to remain otherwise symptomatic. ${ }^{4}$ Peolsson et al ${ }^{3}$ prospectively evaluated a group of patients undergoing ACDF and found only 5 of 34 (15\%) patients were without complaints of neck problems according to the Neck Disability Index (NDI), pain scores, and general health measures at 1 year postoperatively. The prevalence of neck related disability prompted the authors to conclude that improved surgical techniques and postoperative rehabilitation are greatly needed.

With an increase of greater than 200\% in the volume of cervical spine surgeries performed over the last decade, evidence based practices for cervical spine surgeries are becoming increasingly more important. ${ }^{7}$ In the current climate of cost reduction, utilization of rehabilitative services is being examined closely, particularly in situations where there is a lack of evidence regarding their short and/or long term benefits. In particular, there is little data available regarding the best physical therapy practices in this post-operative population. Therefore, to facilitate recommendations for clinical trials or other critical studies regarding postsurgical rehabilitation, we sought to determine the current practice patterns of physical therapists regarding postsurgical rehabilitation techniques and recommendations following cervical spine surgery.

\section{Sample}

Participants were recruited from two private physical therapy practice groups (Select Medical Corporation, New England region $n=100$, Physical Therapy and Sports Medicine Centers of CT $n=35$ ), and the membership of the Connecticut Physical Therapy Associations Orthopedics and Manual Therapy special interest group $\mathrm{n}=48$. Potential subjects received an e-mail inviting them to participate, which contained a link to the on-line survey as well as information regarding the deadline for completion. Participants were informed that the survey would take approximately 10 minutes to complete and that the information gathered for the study was confidential and anonymous. Participants were sent two reminders over a period of two months to aide in recruitment.

\section{METHODS}

The authors developed an internet based survey similar to the survey conducted with the surgical members of the North American Spine Society. ${ }^{2}$ Subjects completed an internet based survey consisting of 21 questions. The first portion of the survey contained questions regarding demographic and training characteristics, including fellowship or residency training, length of the time since the completion of training, specialization, type of practice (academic, private practice, hospital, multispecialty group, other), therapist age, and yearly volume of cervical spine post-operative rehabilitation procedures performed by the individual therapist. The second part of the survey contained questions pertaining to therapist beliefs regarding rehabilitation following $\mathrm{ACDF}$, and the final section contained questions regarding the frequency and duration of postsurgical rehabilitation and specific intervention recommendations following cervical spine surgery. Prior to distribution of the survey, the tool was reviewed by two independent practitioners, one a spine surgeon, one a physical therapist with orthopedic specialist certification for content validation.

Responses were analyzed using uni-variate statistical analyses, including frequencies of responses for categorical variables. Frequency distributions were created for all response variables and bi-variate cross-tabulations were used for comparisons of selected demographic variables with selected practice variables. When appropriate, original responses were collapsed into fewer categories. Chi square tests were used to compare associations between demographic variables and practice-related responses. Finally, a Spearman rho correlation was used to assess the relationship between demographic variables and practice recommendations. All calculations were completed using SPSS Version 16 (IBM SPSS Statistics, Rel. 19.0.0. 2010. Chicago: SPSS Inc., an IBM Company). An alpha-level of $<0.05$ was chosen a priori as the 
threshold for statistical significance and maintained due to the descriptive nature of the study,

\section{RESULTS}

A total of 53 subjects completed the e-mail survey tool, for a total response rate of $29 \%$. Therapist demographics are contained in Table 1.

Table - 1: Demographics and Training Characteristics of Physical Therapists $(\mathrm{N}=53)$

\begin{tabular}{|c|c|c|}
\hline Age & Frequency & Percentage \\
\hline $21-30$ & 21 & 39.6 \\
\hline $31-40$ & 19 & 35.8 \\
\hline $41-50$ & 8 & 15.1 \\
\hline $51-60$ & 5 & 9.4 \\
\hline \multicolumn{3}{|l|}{ Years in practice } \\
\hline $0-5$ years & 18 & 34.0 \\
\hline $6-10$ years & 12 & 22.6 \\
\hline 11-15 years & 6 & 11.3 \\
\hline $16-20$ years & 7 & 13.2 \\
\hline $20-25$ years & 6 & 11.3 \\
\hline $25+$ years & 4 & 7.5 \\
\hline \multicolumn{3}{|l|}{ Practice setting } \\
\hline academic institution & 3 & 5.7 \\
\hline private practice & 33 & 62.3 \\
\hline multispecialty group & 5 & 9.4 \\
\hline $\mathrm{HMO}$ & 2 & 3.8 \\
\hline Other & 10 & 18.9 \\
\hline \multicolumn{3}{|l|}{$\begin{array}{l}\text { Board Certified Clinical } \\
\text { Specialist (OCS,SCS) }\end{array}$} \\
\hline Yes & 9 & 17.0 \\
\hline No & 44 & 83.0 \\
\hline \multicolumn{3}{|l|}{$\begin{array}{c}\text { Fellowship/Residency } \\
\text { Training }\end{array}$} \\
\hline Fellowship/residency & 7 & 13.2 \\
\hline No fellowship/residency & 46 & 86.8 \\
\hline
\end{tabular}

Across all groups, the majority of therapists (58.5\%) started therapy in the 4-6 week range, and typically treat patients following ACDF two sessions per week(66.0\%). There were no statistically significant

differences comparing treatment frequency or start time for practice setting, years of practice, age group, fellowship/ residency training or clinical specialization. (Table 2)

Table - 2: Initiation and Frequency of Therapy $(\mathrm{N}=53)$

\begin{tabular}{|c|c|c|}
\hline Sessions per week & Frequency & Percentage \\
\hline 2 & 35 & 66.0 \\
\hline 3 & 15 & 28.3 \\
\hline 4 & 1 & 1.9 \\
\hline 5 & 1 & 1.9 \\
\hline missing data & 1 & 1.9 \\
\hline Start Time & & \\
\hline first week & 1 & 1.9 \\
\hline 2-3 weeks & 14 & 26.4 \\
\hline 4-6 weeks & 31 & 58.5 \\
\hline pain controlled & 1 & 1.9 \\
\hline radiographic healing & 4 & 7.5 \\
\hline Missing & 2 & 3.8 \\
\hline
\end{tabular}


The majority of therapists (52.8\%) across all groups continue therapy for 4-6 weeks, with 6-8 weeks also occurring frequently (30.2\%). There was a statistically significant difference for fellowship/ residency trained therapists tending to continue therapy longer than non-fellowship/residency trained therapists $\left(\chi^{2}=9.92, p=.019,+\right.$ LR 8.70). There was no statistically significant difference in start timing or sessions per week between fellowship/residency trained therapists and nonfellowship/residency trained therapists. There was an association for specialists to see patients fewer times per week $\left(\chi^{2}=10.74, p=.013,+L R=8.50\right)$, and for therapists with more than 25 years of experience to see patients more frequently $\left(\chi^{2}=\right.$ 28.01, $\mathrm{p}=.022$, $+\mathrm{LR}=19.99$ ). Additionally, there was an association between seeing a higher volume of post operative cases and more sessions per week $\left(\chi^{2}=23.44, p=.024,+L R=14.01\right)$. There were no statistically significant associations between practice setting or age and the start of therapy, visits per week, or length of continuation of therapy.

\section{Appropriate treatment options}

Physical therapists who participated were presented with a list of 11 common treatment modalities, and asked to select from this list the treatments that they deemed to be appropriate for patients following ACDF, and then a duplicate list asking them to select those that they deemed inappropriate for patients following ACDF. The selected treatments are presented in Table 3.

Table - 3: Appropriateness of therapeutic modalities

\begin{tabular}{|c|c|c|c|c|}
\hline & \multicolumn{2}{|c|}{ Deemed appropriate } & \multicolumn{2}{|c|}{ Deemed inappropriate } \\
\hline & $\begin{array}{c}\text { Response } \\
\text { Percent }\end{array}$ & $\begin{array}{c}\text { Response } \\
\text { Count }\end{array}$ & $\begin{array}{c}\text { Response } \\
\text { Percent }\end{array}$ & $\begin{array}{c}\text { Response } \\
\text { Count }\end{array}$ \\
\hline Moist Heat & $86.5 \%$ & 45 & $5.8 \%$ & 3 \\
\hline $\begin{array}{c}\text { Isometric } \\
\text { Strengthening }\end{array}$ & $86.5 \%$ & 45 & $9.6 \%$ & 5 \\
\hline $\begin{array}{c}\text { Endurance } \\
\text { exercises }\end{array}$ & $73.1 \%$ & 38 & $7.7 \%$ & 4 \\
\hline $\begin{array}{l}\text { Stretching } \\
\text { exercises }\end{array}$ & $71.2 \%$ & 37 & $7.7 \%$ & 4 \\
\hline Aerobic exercise & $63.5 \%$ & 33 & $5.8 \%$ & 3 \\
\hline Massage & $61.5 \%$ & 32 & $11.5 \%$ & 6 \\
\hline $\begin{array}{c}\text { Electrical } \\
\text { stimulation }\end{array}$ & $59.6 \%$ & 31 & $21.2 \%$ & 11 \\
\hline $\begin{array}{c}\text { Joint } \\
\text { mobilization }\end{array}$ & $40.4 \%$ & 21 & $40.4 \%$ & 21 \\
\hline Ultrasound & $26.9 \%$ & 14 & $51.9 \%$ & 27 \\
\hline Aquatic therapy & $21.2 \%$ & 11 & $7.7 \%$ & 4 \\
\hline Traction & $5.8 \%$ & 3 & $90.4 \%$ & 47 \\
\hline
\end{tabular}

\section{Treatment prioritization}

The therapists were given a list of 11 common treatments utilized in the treatment of patients in the outpatient setting. They were instructed to rate the interventions on a scale of 1-4, with 1 being not at all important and 4 being very important. The majority of therapists from the total sample identified several treatments as being very important in the care of patients following ACDF. The primary treatments included endurance exercise $(60.4 \%)$, isometric strengthening (56.6\%), and stretching (45.3\%). Secondary treatments, defined as somewhat important, included aerobic activity (somewhat $45.3 \%$, very $35.8 \%$, cumulative $81.1 \%$ ), massage (somewhat $58.5 \%$, very $18.9 \%$, cumulative $77.4 \%$ ), and moist heat (somewhat $45.3 \%$, very $17 \%$, cumulative $62.3 \%$ ). Those rated primarily as "not at all important" were traction (77.4\%) and ultrasound (60.4\%). Mobilization, aquatic therapy and electrical stimulation were considered neutral recommendations, with greater than $50 \%$ of respondents rating these interventions as slightly or somewhat important. (Table 4)

Table - 4: Therapist rankings of interventions 


\begin{tabular}{|c|c|c|c|c|c|c|c|c|}
\hline & \multicolumn{2}{|c|}{$\begin{array}{l}\text { Very } \\
\text { important }\end{array}$} & \multicolumn{2}{|c|}{$\begin{array}{l}\text { Somewhat } \\
\text { Important }\end{array}$} & \multicolumn{2}{|c|}{$\begin{array}{l}\text { Slightly } \\
\text { Important }\end{array}$} & \multicolumn{2}{|c|}{$\begin{array}{l}\text { Not at all } \\
\text { Important }\end{array}$} \\
\hline & $\underline{N}$ & $\underline{\%}$ & $\underline{\mathrm{n}}$ & $\underline{\%}$ & $\underline{\mathrm{N}}$ & $\underline{\%}$ & $\underline{\mathrm{N}}$ & $\underline{\%}$ \\
\hline Endurance & 32 & 60.4 & 13 & 24.5 & 7 & 13.2 & 0 & 0 \\
\hline $\begin{array}{l}\text { Isometric } \\
\text { Strength }\end{array}$ & 30 & 56.6 & 16 & 30.2 & 4 & 7.5 & 3 & 5.7 \\
\hline Stretching & 24 & 45.3 & 16 & 30.2 & 10 & 18.9 & 2 & 3.8 \\
\hline $\begin{array}{l}\text { Aerobic } \\
\text { Activity }\end{array}$ & 19 & 35.8 & 24 & 45.3 & 10 & 18.9 & & \\
\hline $\begin{array}{c}\text { Joint } \\
\text { Mobilization }\end{array}$ & 10 & 18.9 & 13 & 21.5 & 12 & 22.6 & 15 & 28.3 \\
\hline Massage & 10 & 18.9 & 31 & 58.5 & 7 & 13.2 & 4 & 7.5 \\
\hline Moist Heat & 9 & 17.0 & 24 & 45.3 & 13 & 21.5 & 7 & 13.2 \\
\hline $\begin{array}{c}\text { Electrical } \\
\text { Stimulation }\end{array}$ & 6 & 11.3 & 18 & 34.0 & 13 & 21.5 & 11 & 20.8 \\
\hline Aquatic & 2 & 3.8 & 12 & 22.6 & 22 & 41.5 & 13 & 21.5 \\
\hline Traction & 2 & 3.8 & 3 & 5.7 & 2 & 3.8 & 41 & 77.4 \\
\hline Ultrasound & 1 & 1.9 & 9 & 17.0 & 9 & 17.0 & 32 & 60.4 \\
\hline
\end{tabular}

There was a significant association between fellowship or residency training and the prioritization of joint mobilizations $\left(\chi^{2}=8.40, p=\right.$. 038, $+\mathrm{LR}=8.99$ ). Specialists considered stretching to be a lower priority intervention compared to nonspecialists $\left(\chi^{2}=12.11, p=.007,+L R=10.91\right)$. There was a strong association for those identifying as working in private practice, academic settings and "other" as considering isometric strengthening important compared to those identifying as working for an HMO $\left(\chi^{2}=30.26, p=.003,-L R=18.06\right)$. There were no other statistically significant associations between groups and specific interventions.

There were several significant correlations between demographic variables and treatment prioritization. Amongst the demographic variables, years of practice was negatively correlated to specialist status, $(\mathrm{r}=-.374, \mathrm{p}=.006)$, however there were no other statistically significant relationships between years of practice, specialist certification, and fellowship status. Therapists who prioritized endurance activity also selected aerobic exercise as an important treatment aspect, $(\mathrm{r}=.557, \mathrm{p}<.001)$. This finding was not significantly related to specialist status, years in practice, or fellowship status. Despite the general response regarding modalities being appropriate but of lower priority, there was a strong relationship for therapists who indicated that ultrasound was important also indicating that electrical stimulation $(r=.450$, $\mathrm{p}=.001)$ and moist heat $(\mathrm{r}=.397, \mathrm{p}=.004)$ were also important. However, there was a moderate to strong relationship between prioritizing mobilizations and avoiding moist heat $(\mathrm{r}=-.349$, $p=.013)$. These findings did not correlate to years of practice, or specialist certification, but modality use was correlated to a lack of fellowship training
(ES $\mathrm{r}=.350, \mathrm{p}=.015, \quad$ US $\mathrm{r}=.278, \mathrm{p}=.048, \mathrm{MH}$ $\mathrm{r}=.344, \mathrm{p}=.012$ ). Inclusion of isometric exercises was negatively correlated to the length of continuation of therapy, $(r=-.303, p=.029)$ without relationship to demographic factors. However, fellowship training also had a moderate negative correlation to length of continuation of therapy ( $\mathrm{r}=$ $-.395, \mathrm{p}=.004)$.

Therapist Beliefs Regarding Rehabilitation Following ACDF

The therapists were asked to rate their beliefs on a scale of 1-5, with 1 indicating strongly disagree and 5 indicating strongly agree with a series of statements.

In response to the statement "I believe that physical therapy is beneficial to the patient following cervical fusion surgery", 57.7\% $(n=30)$ indicated strongly agree, $36.5 \%(\mathrm{n}=19)$ indicated agree, 3.8\% $(\mathrm{n}=2)$ indicated neutral, and $1.9 \%(\mathrm{n}=1)$ strongly disagreed.

In response to the statement "I believe that physical therapy may be harmful to the healing of the fusion", no participants responded strongly agree, 5.9\% $(\mathrm{n}=3)$ indicated agree, $7.8 \%(\mathrm{n}=4)$ indicated neutral, $64.7 \%(\mathrm{n}=33)$ indicated disagree, and $21.6 \%(\mathrm{n}=11)$ indicated strongly disagree.

In response to the statement "I believe that the patient is able to recover full function without post operative intervention", no participant responded strongly agree, 9.6\% $(n=5)$ agreed, 34.6\% $(n=18)$ indicated neutral, $42.3 \%(\mathrm{n}=22)$ indicated disagree, and $13.5 \%(n=7)$ indicated strongly disagree.

In response to the statement "My patients have had negative experiences with post-operative physical therapy", no participant responded strongly agree, 
3.8\% $(\mathrm{n}=2)$ indicated agree, $7.7 \%(\mathrm{n}=4)$ indicated neutral, $53.8 \%(\mathrm{n}=28)$ indicated disagree, and $34.6 \%(\mathrm{n}=18)$ indicated strongly disagree.

In response to the statement, "Patients have better outcomes with the inclusion of post-operative physical therapy", 44.2\% ( $\mathrm{n}=23)$ indicated strongly agree, $46.2 \%(n=24)$ indicated agree, $7.7 \%(n=4)$ indicated neutral, and $1.9 \%(\mathrm{n}=1)$ indicated $\mathrm{s}$ trongly disagree. There were no statistically significant associations between response and any grouping for age, fellowship/residency training, practice setting, clinical specialist status, or years of practice across all measures for therapist belief.

\section{Correlations of beliefs}

Therapist response that therapy is beneficial to the patient was strongly correlated to patients having improved outcomes with post operative therapy, $\mathrm{r}=.591, \mathrm{p}<.001$. This response was negatively correlated to believing that patients could achieve full function without post operative care $(r=-.412$, p-.002), as well as reporting that patients have had negative experiences with therapy $(r=-.527$, $\mathrm{p}<.001)$. Responses indicating that patients achieve superior outcomes with therapy also demonstrated a negative correlation to believing that patients could achieve full function without post operative care $(\mathrm{r}=-.500, \mathrm{p}<.001)$, as well as reporting that patients have had negative experiences with therapy $(r=-.416, p=.002)$. However, for therapists reporting that they felt therapy may be harmful to the fusion, there was a statistically significant correlation to reporting that their patients have had negative outcomes as a result of therapy $(r=.284$, $\mathrm{p}=.041)$.

\section{DISCUSSION}

The purpose of this study was to establish physical therapists current practice patterns and beliefs regarding rehabilitation following ACDF, establishing data regarding usual physical therapy care during the post-operative period. To our knowledge, there has not been specific research performed to determine either the role of physical therapy following ACDF surgery or the types of therapy performed. Therefore, establishment of baseline data is required to develop appropriate protocols for comparison of various modes of care for use in post-operative rehabilitation studies.

The results of this study revealed several trends in clinical care following ACDF. Therapists strongly believed that post-operative rehabilitation results in improved functional outcomes that would not have been attained by the patient on their own. This is in line with the current evidence suggesting that while pain is resolved following ACDF, other deficits remain. ${ }^{1,6,8}$ Therapists emphasized the use of active rehabilitation featuring endurance exercises, isometric strengthening, stretching, and aerobic activity, while placing a lower emphasis on passive modalities. The majority of respondents reported initiation of therapy between 4-6 weeks. As most patients would then be beyond the acute stage of healing, pain management may be a lower priority, and passive modalities may be underrepresented as a result. Interestingly, while the majority of therapists deemed modalities to be appropriate, very few placed a high priority on their usage in this population. Those therapists indicating a higher priority of ultrasound, however, were also likely to place a high priority on moist heat and electrical stimulation. This may represent an alternative practice pattern for this post operative population.

We were unable to identify any randomized trials evaluating the effects of physical therapy during the post-operative period following cervical spine surgery. Findings from observational studies have elucidated various factors related to disability following ACDF. Previous research ${ }^{9}$ found an association between decreased neck muscle endurance and continued pain and disability following ACDF. Neck muscle endurance (NME) deficits were directly correlated to higher levels of disability suggesting that specific training for NME should be incorporated into the rehabilitation program. Additional studies ${ }^{3}$ examined short term results following ACDF (6 months) to see if long term results (3 years) could be predicted. At three years after ACDF, approximately two-thirds of the patients had deficits related to pain intensity and function. These findings led to the conclusion that while these problems are multi-factorial, the inclusion of strength and endurance activities may improve long-term outcome.

Based on the consensus of respondents, there is a strong feeling that patients benefit from the inclusion of post-operative rehabilitation. The specific recommendations included endurance exercises, isometric strengthening, stretching, aerobic activity, and to a lesser extent massage and moist heat. These active treatment interventions appear to be specifically targeted at restoring function rather than provide symptomatic relief. This also coincided with a strong recommendation away from passive modalities such as ultrasound and traction in the post-operative period. Incorporating appropriate active rehabilitation following fusion may lead to better results and decreased overall expenditures. As such, our findings are in agreement with the suggestions of previous authors. 
Manual therapy has been supported by the best available evidence for the treatment of cervical radiculopathy, ${ }^{10,11}$ however there seems to be a general lack of consensus regarding the use of joint mobilizations following ACDF. In fact, our sample presented with a near equal distribution of answers regarding the prioritization of its use. While certainly contraindicated at the level of fusion, there may be a role for manual therapies directed at the surrounding levels/tissues. Current theories, including regional interdependence ${ }^{12,13}$, as well as the neurophysiologic effect of manual therapies on pain modulation ${ }^{14}$ may justify a role for such techniques in the management of patients following ACDF. The association of mobilization use with fellowship-residency training may represent a selection bias, as these individuals are more likely to have specialized training in the use of manual therapy techniques. This training, however, would also qualify these individuals the experts in the use of these techniques, and may indicate an area in need of further study.

In our sample, there was an association for specialists to see patients fewer times per week. This corresponds to previous findings regarding the care of neck pain relative to education. Magel et $\mathrm{al}^{15}$ reported that the number of sessions of care decreased in response to specific education regarding care of neck pain. Conversely, in the current study, therapists indicating $>25$ years of experience was strongly associated with seeing patients more frequently. While we could find no direct data associating experience to therapy utilization, prior research has reported on the association of experience to evidence based practice. ${ }^{16}$ Their findings indicated a strong association with younger/less experienced physical therapists utilizing evidence and performing critical appraisal to aide their practice, while progressive years of experience were associated with a decreased use of evidence. They reported that therapists with <5yrs experience reported a $4.6 \mathrm{x}$ greater use of evidence when compared to therapists with $15 \mathrm{yr}+$ years of experience. Concurrently, therapists in the 20-29 year old range reported that they were $22.7 x$ more likely to have received formal training in critical appraisal when compared to therapists in the 50yo + category. The current study population demonstrated a negative correlation between years in practice and specialist certification. As a result, the reported high levels of therapy utilization in the more experienced group may be related to the reported trend towards lower levels of evidenced based practice.

There were several limitations for this study. The survey was only issued to a single geographic region, and may have detected only local practice patterns. These patterns and beliefs may not be those of therapists in other regions. While intended to determine current practice, our survey did not differentiate whether treatment choice was at the therapist's discretion or if it was prescriptive in nature, nor did we attempt to differentiate treatment choice based on the immediate goals of treatment, instead focusing on a more global view of ACDF rehabilitation. Our sample was heavily weighted towards therapists in a private practice setting, and one-third of respondents were novice practitioners with less than 5 years of experience. It should therefore be noted that due to a limited sample size, as well as a possible selection bias from the sample of convenience who chose to participate, these findings may not be applicable to all rehabilitative settings. While the response rate of $29 \%$ was better than generally expected for a survey instrument, and the overall sample of 53 is large enough to allow for some generalizations to be made, there is also a possibility of selection bias, as those who chose to respond may have different practice patterns and beliefs than those who chose not to respond. Finally, the survey instrument utilized to perform this study has not been subjected to statistical validation.

\section{CONCLUSION}

The results of the study indicate several recommendations for the utilization of physical therapy following ACDF. Over 90\% of therapists surveyed believe that therapy is beneficial for the patient following ACDF. Therapy is utilized in most cases twice weekly, and for 6 weeks duration. During these sessions, the focus is on endurance exercises, isometric strengthening, stretching, aerobic activity, and to a lesser extent massage and moist heat. These active treatment interventions appear specifically targeted to regain function rather than provide symptomatic relief. Future research to examine the efficacy of postoperative rehabilitation in improving clinical outcomes and preventing disability in patients who have undergone ACDF is needed.

Acknowledgements: The authors would like to thank Ms. Lindsay McDermott and Mr. Mark Gombotz of Select Medical Corp. and Mr. Michael Gans of Physical Therapy and Sports Medicine Centers/Connecticut Physical Therapy Association OMT SIG for their assistance in the recruitment of participants for this study, and Dr. Mark Cote for his assistance in editing this paper. The authors also thank R. Alexander Mohr, MD and Sean P. Riley PT, ScD, OCS for their assistance in the content validation for this survey. 
This research received no specific grant from any funding agency in the public, commercial, or notfor-profit sectors.

\section{REFERENCES}

1. Hessler C, Boysen K, Regelsberger J, Vettorazzi E; Winkler D, Westphal M. Patient Satisfaction After Anterior Cervical Discectomy and Fusion Is Primarily Driven by Relieving Pain. Clinical Journal of Pain. 2012;28(5):398-403.

2. Checo FJ, Swanson B, Leger R, Mohr RA. Cervical Spine Postoperative Practice Patterns: Variations in cervical collar, imaging and physical therapy utilization. SpineLine. 2012:2730.

3. Peolsson A, Vavruch L, Oberg B. Can the results 6 months after anterior cervical decompression and fusion identify patients who will have remaining deficit at long-term? Disabil Rehabil. 2006;28(2):117-24.

4. Hacker RJ, Cauthen JC, Gilbert TJ, Griffith SL. A prospective randomized multicenter clinical evaluation of an anterior cervical fusion cage. Spine. 2000;25(20):2646-54.

5. Casha S, Fehlings MG. Clinical and radiological evaluation of the Codman semiconstrained loadsharing anterior cervical plate: prospective multicenter trial and independent blinded evaluation of outcome. J Neurosurg. 2003;(99: Suppl):264-70.

6. Peolsson A, Peolsson M. Predictive factors for long-term outcome of anterior cervical decompression and fusion: a multivariate data analysis. Eur Spine J. 2008;17(3):406-14.

7. Wang MC, Kreuter W, Wolfla CE, Maiman DJ, Deyo RA. Trends and variations in cervical spine surgery in the United States: Medicare beneficiaries, 1992 to 2005. Spine. 2009;34(9): 955-61.

8. Peolsson A, Vavruch L, Öberg B. Disability after Anterior Decompression and Fusion for Cervical Disc Disease. Adv Physio. 2002;4(3):111-24.
9. Peolsson A., Kjellman G. Neck muscle endurance in nonspecific patients with neck pain and in patients after anterior cervical decompression and fusion. $\mathrm{J}$ Manipulative Physiol Ther. 2007 Jun;30(5):343-50.

10. Salt E, Wright C, Kelly S, Dean A. A systematic literature review on the effectiveness of noninvasive therapy for cervicobrachial pain. Man Ther. 2011;16(1):63-5.

11. Hurwitz E, Carragee E, van der Velde G, Carroll L, Nodin M, Guzman J,et al. Treatment of Neck Pain: Noninvasive Interventions Results of the Bone and Joint Decade 2000-2010 Task Force on Neck Pain and Its Associated Disorders. Eur Spine J. 2008;17(suppl 1):123-52.

12. Wainner R, Whitman J, Cleland J, Flynn $\mathrm{T}$. Regional Interdependence: A Musculoskeletal Examination Model Whose Time Has Come. J Orthop Sports Phys Ther. 2007;37(11):658-60.

13. Cleland JA, Childs JD, McRae M, Palmer JA, Stowell T. Immediate effects of thoracic manipulation in patients with neck pain: a randomized clinical trial. Man Ther. 2005;10(2):127-35.

14. Sterling M, Jull G, Wright A. Cervical mobilisation: concurrent effects on pain, sympathetic nervous system activity and motor activity. Man Ther. 2001;6(2):72-81.

15. Magel J, Cleland JA, Fritz JM, Brennan G. Does Continuing Education Improve Physical Therapists' Effectiveness in Treating Neck Pain? A Randomized Clinical Trial. Phys Ther. 2008;89(1):38-47.

16. Jette DU, Bacon K, Batty C, Carlson M, Ferland A, Hemmingway RD, et al. Evidence-Based Practice: Beliefs, Attitudes, Knowledge, and Behaviors of Physical Therapists. Phys Ther. 2003;83(9):786-805.

\section{Citation}

Brian T. Swanson, Robin R. Leger. (2015). PHYSICAL THERAPY FOLLOWING ANTERIOR CERVICAL DISCECTOMY AND FUSION: A STUDY OF CURRENT CLINICAL PRACTICE AND THERAPIST BELIEFS. International Journal of Physiotherapy, 2(2), 399-406. 